\title{
Investigation of unilateral sensory or motor symptoms: frequency of neurological pathology depends on side of symptoms
}

\author{
Peter Rothwell
}

\begin{abstract}
The records of 82 patients who had undergone inpatient neurological investigation for unilateral motor symptoms, sensory symptoms, or both, without definite neurological signs, were reviewed. Diagnosis of a physical disorder was more frequent if symptoms were on the right side rather than on the left (odds ratio $(O R)=7 \cdot 7,95 \%$ confidence interval (95\% CI) $2 \cdot 6-23)$, and in males than in females $(\mathrm{OR}=3 \cdot 0,95 \%$ CI 1·1-8・3).
\end{abstract}

(F Neurol Neurosurg Psychiatry 1994;57:1401-1402)

Sensory or motor disturbance in one or more limbs is a common reason for referral to neurology outpatient clinics. ${ }^{1}$ Symptoms are often unilateral and many patients have no neurological signs. Possible diagnoses include migraine, partial seizures, transient ischaemic attack, and multiple sclerosis. Most patients without signs are reassured and discharged without investigation, but in some cases further investigation is considered necessary. This study aimed to assess the frequency of neurological pathology in patients with unilateral sensory symptoms, motor symptoms, or both, without definite neurological signs, admitted for inpatient investigation. Because hyperventilation ${ }^{23}$ and conversion hysteria ${ }^{45}$ are associated with predominantly left sided symptoms, a second aim was to determine whether the frequency of pathology, and therefore the need for more intensive investigation, could be predicted by the lateralisation of symptoms in a more general group of patients with unilateral symptoms.

\section{Methods}

Discharge summaries of patients under 60 years of age who had undergone inpatient investigation by the medical neurologists in Edinburgh from 1987 to 1993 were reviewed. The case records of patients fulfilling the following criteria were then examined: (a) unilateral paraesthesia, numbness, or weakness involving one arm and/or the ipsilateral leg, in which pain was not a prominent feature; (b) no other focal neurological symptoms; (c) no definite signs elicited on neurological examination. Patients with mild or variable weakness, sensory loss, mild reflex asymmetry, and equivocal plantar response were, however, included.

All patients had been investigated as considered appropriate by their neurologist. Investigation was taken as positive if it suggested a diagnosis of a physical disorder that would account for the patient's symptoms.

\section{Results}

Eighty two cases fulfilling the criteria were identified. Investigations indicating a physical disorder were found in 22 cases $(27 \%, 95 \%$ confidence interval (95\% CI) 18-38\%): multiple sclerosis (nine), other spinal cord pathology (five), transient ischaemic attack (five), epilepsy (one), arteriovenous malformation (one), and hypoglycaemia (one). Thirty eight $(18 \%)$ of the 209 investigations performed, excluding routine blood tests, were abnormal (table 1). The number of investigations performed was not related to the side of symptoms or to the sex of the patient.

Diagnoses of a physical disorder (table 2) were more frequent in patients with right sided than with left sided symptoms (odds ratio $(\mathrm{OR})=7 \cdot 7,95 \%$ CI $2 \cdot 6-23$ ). This was true for patients with sensory symptoms alone (OR $=6 \cdot 7,95 \%$ CI $1 \cdot 6-28)$ and for patients with motor symptoms with or without a sensory accompaniment $(\mathrm{OR}=9.3,95 \% \mathrm{CI}$ $1 \cdot 8-50)$. Physical diagnoses were more frequent in males than females (OR $=3 \cdot 0,95 \%$ CI 1.1-8.3), and considerably more frequent in males with right sided symptoms than in females with left sided symptoms $(O R=21$,

Table 1 Specialist investigations performed on the 82 cases and number of abnormal results obtained

\begin{tabular}{lll}
\hline Investigation & $\begin{array}{l}\text { No cases } \\
\text { investigated } \\
(\%)\end{array}$ & $\begin{array}{l}\text { No } \\
\text { abnormal } \\
(\%)\end{array}$ \\
\hline Brain CT & $52(59)$ & $6(12)$ \\
Lumbar puncture & $51(58)$ & $5(10)$ \\
Visual evoked potentials & $29(33)$ & $2(7)$ \\
Magnetic resonance imaging & $19(22)$ & $4(21)$ \\
Myelogram & $13(15)$ & $4(31)$ \\
Somatosensory evoked potentials & $13(15)$ & $1(8)$ \\
Nerve conduction studies & $11(13)$ & $2(18)$ \\
Carotid duplex ultrasound & $8(10)$ & $6(75)$ \\
Carotid arterial angiography & $6(7)$ & $6(100)$ \\
Electroencephalogram & $4(5)$ & $0(0)$ \\
24 hour electroencephalogram & $2(2)$ & $1(50)$ \\
48 hour fast & $1(1)$ & $1(100)$ \\
\hline
\end{tabular}


Table 2 Number of identifiable physical diagnoses in patients grouped by sex and lateralisation of symptoms

\begin{tabular}{|c|c|c|c|c|c|c|}
\hline \multirow{2}{*}{$\begin{array}{l}\text { Side of } \\
\text { symptom }\end{array}$} & \multirow{2}{*}{$\begin{array}{l}\text { Physical } \\
\text { diagnosis }\end{array}$} & \multicolumn{3}{|l|}{ Symptoms } & \multicolumn{2}{|l|}{ Sex } \\
\hline & & Sensory & Motor & All & $M$ & $F$ \\
\hline $\begin{array}{l}\text { Right } \\
\text { Right } \\
\text { Left } \\
\text { Left }\end{array}$ & $\begin{array}{l}\text { Yes } \\
\text { No } \\
\text { Yes } \\
\text { No }\end{array}$ & $\begin{array}{r}8 \\
8 \\
4 \\
27\end{array}$ & $\begin{array}{r}7 \\
5 \\
3 \\
20\end{array}$ & $\begin{array}{r}15 \\
13 \\
7 \\
47\end{array}$ & $\begin{array}{r}9 \\
3 \\
2 \\
12\end{array}$ & $\begin{array}{r}6 \\
10 \\
5 \\
35\end{array}$ \\
\hline $\begin{array}{l}\text { Odds ratio } \\
\text { (95\% CI) }\end{array}$ & & $\begin{array}{l}6 \cdot 7 \\
(1 \cdot 6-28)\end{array}$ & $\begin{array}{c}9 \cdot 3 \\
(1 \cdot 8-50)\end{array}$ & $\begin{array}{c}7 \cdot 7 \\
(2 \cdot 6-23)\end{array}$ & $\begin{array}{l}18 \cdot 0 \\
(2 \cdot 5-131)\end{array}$ & $\begin{array}{l}4 \cdot 2 \\
(1 \cdot 1-17)\end{array}$ \\
\hline
\end{tabular}

95\% CI 4-105). Two patients were noted to be left handed. Both had right sided symptoms and negative investigations.

In 17 cases, the diagnosis of anxiety and hyperventilation syndrome was suspected at presentation. Of the 16 of these in whom no physical diagnosis was found, 15 had left sided symptoms. Nine patients with no physical diagnosis were diagnosed as depressed by a psychiatrist during their inpatient stay. Eight of these had right sided symptoms (OR $=120,95 \%$ CI 4-105).

\section{Discussion}

Most patients under 60 years of age, with unilateral sensory or motor disturbance without definite clinical signs, admitted for inpatient investigation, seem to have no identifiable neurological disorder. Although investigation was thorough, long term follow up would strictly be necessary to exclude serious physical pathology. The prevalence of pathology in outpatients with such symptoms is likely to be lower still, as only the small proportion of cases considered to merit inpatient investigation were studied.

The excess of women in this study and their lower frequency of pathology compared with males, may indicate a greater prevalence of psychosomatic symptoms in women, but selection bias cannot be excluded. The higher incidence of multiple sclerosis in women might increase clinical suspicion and hence the likelihood of inpatient investigation.

Patients with unilateral sensory, or motor symptoms, or both without definite clinical signs, are nearly eight times more likely to have an identifiable physical disorder if symptoms are on the right rather than on the left. Hyperventilation often causes left sided sensory symptoms, ${ }^{23}$ but would not explain the lateralisation of motor symptoms in this study. Preferential lateralisation of symptoms to the left side is also seen in conversion hysteria. $^{45}$ The excess of pathology associated with right sided symptoms is unlikely to be an artefact. If the investigating neurologists were aware of the association between psychological diagnoses and left sided symptoms, it is likely that they would have been biased towards more stringent selection of cases with left sided symptoms for inpatient investigation, resulting in a higher rate of diagnoses of physical disorders.

The association of provisional diagnoses of anxiety and hyperventilation with left sided symptoms is not unexpected, but the association of depression with right sided symptoms has not been noted previously. The association may be due to chance, or may be due to a bias in favour of the referral of patients with right sided symptoms, who might be perceived to be unlikely to be hyperventilating, for further psychiatric assessment. The opposite lateralisation of symptoms in anxiety and depression, however, is consistent with evidence of functional hemispheric asymmetry during altered mood. During anxiety states, perception of left sided visual and auditory stimuli is increased, ${ }^{67}$ whereas perception is greatest for right sided stimuli in depression. ${ }^{8} 9$

The results of this study are not strictly generalisable to a wider population, but do suggest that in right handed patients complaining of unilateral sensory or motor symptoms, without definite neurological signs, a physical disorder is less likely if the symptoms are on the left side. No conclusions can be drawn regarding left handed subjects due to insufficient numbers. This information may help physicians to reassure patients in whom they feel a physical disorder is unlikely, and may support their clinical suspicions in those they think require further investigation.

I thank Dr Roger Cull and Professor Charles Warlow for their advice regarding the performance of the study and preparation of the manuscript.

1 Stevens DL. Neurology in Gloucestershire: the clinical workload of an English neurologist. $\mathcal{F}$ Neurol Neurosurg Psychiatry 1989;52:439-46.

2 Perkin GD, Joseph R Neurological manifestations of the hyperventilation syndrome. $₹ R$ Soc Med 1986;79: hyperventil.

3 Blau JN, Wiles CM, Solomon FS. Unilateral somatic symptoms due to hyperventilation. $B M \mathcal{F}$ 1983;286: 1108

4 Stern DB. Lateral distribution of conversion reactions. f Nerv Ment Dis 1977;164:122-8.

5 Galin D, Diamond R, Braff D. Lateralisation of conversion symptoms: more frequent on the left. Am $\mathcal{F}$ Psychiatry 1977;134:578-80.

6 Liotti M, Sava D, Rizzolatti G, Carrarra PI. Differential hemispheric asymmetries in depression and anxiety: a reaction time study. Biol Psychiatry 1991;29:887-99.

7 Tucker DM. Lateral brain function, emotion and conceptualisation. Psychol Bull 1981;89:19-46.

8 Tucker DM, Antes JR, Stenslie CE, Barnhardt TN. Anxiety and lateral cerebral function. F Abnorm Psychol 1978;87:380-3.

9 Gruzelier JH. Individual differences in dynamic process asymmetries in normal and pathologic brain. In: Glass $\mathrm{A}$, ed. Individual differences in hemispheric specialisation New York: Plenum, 1979. 